\title{
Strategy of speed restriction allowing extended running times to minimize energy consumption and passenger disutility
}

\author{
N. Kimura \& M. Miyatake \\ Sophia University, Japan
}

\begin{abstract}
Due to a power crisis caused by the Great East Japan Earthquake on 11 March 2011 and the subsequent accident of Fukushima Daiichi nuclear power station, electrical energy consumption used in every sector including railway operators was restricted by the government in the summer of the same year. Since then, railway manufacturers, operators and research organizations have developed technologies of reducing train energy consumption. Improvement of scheduling and train speed control for energy-savings only needs software-based improvements that lead to less cost and time. The authors consider "restraining maximum speed of the train allowing extended running times" in order to reduce train energy consumption against power crisis or substation failure. The problem was defined as a multiobjective optimization problem. Energy consumption and total incremental trip time were calculated as objective functions by using speed profile simulation. The total incremental trip time was calculated with the increased sum of all passengers' running, stoppage and waiting times by speed restriction. All the feasible combinations of setting maximum speed restriction for each train were tested to find the pareto-optimal solutions. The final solutions which are better than the curtailed train service were selected from the paretooptimal solutions. The efficacy of the proposed method was demonstrated with a case study of one direction service of a double track commuter line.

Keywords: power crisis, energy-saving, multiobjective optimization, trip time, maximum speed restriction, pareto-optimal solutions.
\end{abstract}




\section{Introduction}

Electric railway is regarded as "Eco-friendly" transportation in terms of fewer carbon dioxide emission of trains. However, due to a power crisis caused by the Great East Japan Earthquake on 11 March 2011 and the subsequent accident of Fukushima Daiichi nuclear power station, electrical energy consumption used in every sector including railway operators was restricted by $15 \%$ by the government in the summer of the same year. After that, railway manufacturers, operators and research organizations have developed technologies of reducing train energy consumption [1]. The countermeasures of electrical and mechanical loss reduction of motors, inverters etc. and effective reuse of regenerative energy by means of energy storage etc. need some new expensive hardware installation. On the other hand, improvement of scheduling and train speed control for energy-savings only needs software-based improvements that lead to less cost and time. It is essentially suitable to cope with such kind of emergent situation.

There are some ideas of train schedules considering emergent energy savings:

1. Reduced number of cars per train. The train length is reduced.

2. Curtailed train service. Headway is increased.

3. Slow down [2-4]. Maximum speed is restricted. Train running time at a stretch is increased.

4. Reduced number of stops [5]. Some of trains skip some stops in order to reduce maximum speed with keeping the same running time at a stretch.

These are compared in Table 1.

Since it is easy for operators, some railway operators carried out curtailed train services at the daytime on weekdays when electrical energy consumption was restricted by the government on the morrow of the Great East Japan Earthquake. They kept within bounds; however had a bad influence on the convenience and the safety of the users, namely, increased waiting times and so on.

Table 1: Effect of each train schedule.

\begin{tabular}{|c|c|c|c|c|}
\hline & $\begin{array}{c}\text { Reduced } \\
\text { number of } \\
\text { cars }\end{array}$ & $\begin{array}{c}\text { Curtailed } \\
\text { train service }\end{array}$ & Slow down & $\begin{array}{c}\text { Reduced } \\
\text { number of } \\
\text { stops }\end{array}$ \\
\hline Peak power & very good & fair & fair & fair \\
\hline Energy consumption & very good & very good & very good & very good \\
\hline Car re-scheduling & bad & good & fair & very good \\
\hline Crew re-scheduling & very good & good & fair & very good \\
\hline Transport capacity & fair & fair & good & very good \\
\hline $\begin{array}{c}\text { Increase of } \\
\text { passengers' trip times }\end{array}$ & good & bad & fair & fair \\
\hline $\begin{array}{c}\text { Ease of guidance for } \\
\text { passengers }\end{array}$ & very good & good & fair & bad \\
\hline
\end{tabular}

From Table 1, it is obvious that " 3 . slow down" is the only idea that has no serious drawbacks. Therefore, in this study, the authors consider the train 
schedule including the driving method restraining maximum speed of the train allowing extended running times in order to reduce not only train energy consumption, but also these influences. Finally, the proposed train schedules are compared with curtailed train service in terms of both train energy consumption and the convenience of all passengers.

\section{Theory}

\subsection{Speed profile and calculation method of train energy consumption}

Speed profile describes trains position, velocity and running time per interstation. They are calculated by solving the equations of motion based on car performance, train set length, line condition and so on. It is used when running time between stations is decided or train energy consumption is considered. Distance is shown by horizontal axis. Velocity and time are shown by vertical axis. conversion

Once the speed profile is derived, train consumed electrical power $P$ is calculated as (1).

$$
P=E \cdot I=\eta \cdot F \cdot v
$$

where $E$ : collecting voltage

$I$ : collecting current

$\eta$ : energy conversion efficiency

$F:$ tractive/braking effort

$v:$ train speed.

It is calculated from mechanical power by multiplying energy conversion efficiency that is assumed constant in this study. Thus, train energy consumption $P_{w}$ is calculated by the integral of power as (2).

$$
P w=\int P d t
$$

In this study, the train speed profile generator SPEEDY [6] is used by designating driving and line condition. It was developed by Railway Technical Research Institute and used as a trustworthy tool in Japan.

\subsection{Total incremental trip time}

In this study, total incremental trip time is regarded as the indicator of the convenience of all passengers. It is calculated with the increased sum of all passengers' running, stoppage and waiting times per hour compared with normal train schedule.

In order to evaluate the total passengers' trip times, demand data are needed. The demand is given as an Origin-Destination (OD) table. 
Analysis of the flow of the passenger is the simulation which calculates the sum of all passengers' running, stoppage and waiting times per train by giving OD table. The sum of these times is called trip times.

\subsection{Pareto-optimization [7]}

Optimization problem which considers two or more cost functions is called a multiobjective optimization problem. There are some methods solving the problem. In this study, the authors introduce the method considering trade-off relationship between two cost functions. The method is called paretooptimization. Figure 1 shows the concept of pareto-solutions.

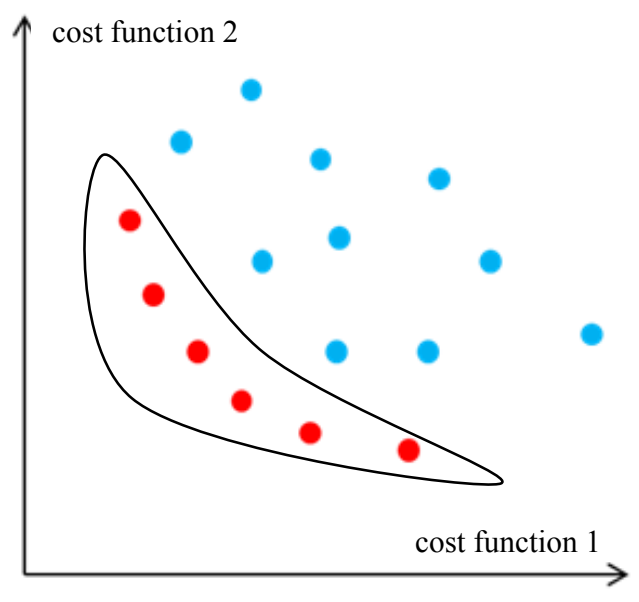

Figure 1: Concept of pareto-solutions.

Figure 1 describes in terms of two objective functions and consider minimization problem. The definition of pareto-solutions is that there is no relative merit between the solutions. Thus, in figure 1, solutions surrounded with a curve are pareto-solutions.

\section{Conditions of simulation}

\subsection{Line condition}

The authors selected a part of typical Japanese urban commuter line with 9 stations as figure 2 (not considering curve or gradient). All trains considered are local trains from the station A to I. Dwell time is 20 seconds each station.

\subsection{Given timetable}

The normal train schedule is composed of 11 trains per hour, so the headway is 5.5 minutes as in Figure 3. Likewise, the proposed timetable including the 
driving method restraining maximum speed is also defined as 11 trains per hour as in Figure 4. From Figure 4, one can find that the average headway is kept the same as that of the normal one. On the other hand, train curtailed schedule is defined as 9 trains per hour, so the headway is 6.7 minutes.



Figure 2: Line condition.

station

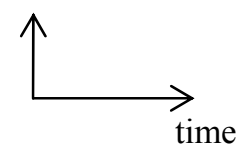

5.5 minutes

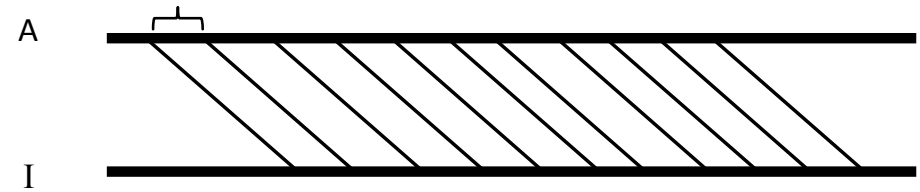

Figure 3: Normal timetable.

5.5 minutes

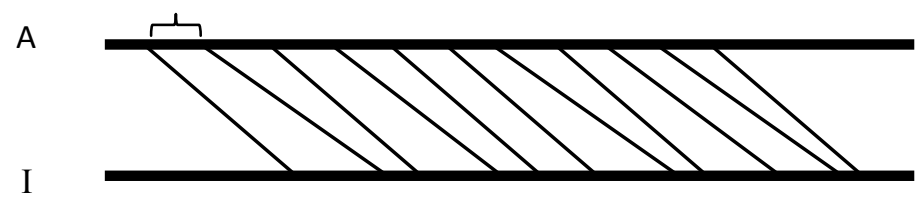

Figure 4: Timetable including the driving method restraining maximum speed.

\section{7 minutes}



Figure 5: Timetable of train curtailed schedule. 


\subsection{Car condition}

In this study, a typical commuter train widely used in Tokyo metropolitan area is assumed. The specifications of the train are tabulated in Table 2.

Table 2: Specifications of a train [8].

\begin{tabular}{|c|c|}
\hline Train set & 10 cars $(6 \mathrm{M} 4 \mathrm{~T})$ \\
\hline Size (length $\cdot$ width $\cdot$ high) of a car & $20000 \mathrm{~mm} \times 2950 \mathrm{~mm} \times 3640 \mathrm{~mm}$ \\
\hline Maximum speed & $120 \mathrm{~km} / \mathrm{h}$ \\
\hline Starting acceleration & $2.5 \mathrm{~km} / \mathrm{h} / \mathrm{s}$ \\
\hline Acceleration & $3.0 \mathrm{~km} / \mathrm{h} / \mathrm{s}$ \\
\hline Deceleration & $5.0 \mathrm{~km} / \mathrm{h} / \mathrm{s}$ \\
\hline Weight & $313 \mathrm{t}(\mathrm{empty})$ \\
\hline Electrical mode & DC $1500 \mathrm{~V}$ \\
\hline
\end{tabular}

\subsection{Number of passengers}

Table 3 shows the OD table of normal or the proposed schedule per train. When the trip times are calculated for the curtailed schedule, each value is multiplied by $6.7 / 5.5$ considering the difference of headways.

Table 3: OD table of normal or the proposed schedule per train.

\begin{tabular}{|c|c|c|c|c|c|c|c|c|}
\hline $\mathrm{O} \backslash \mathrm{D}$ & $\mathrm{B}$ & $\mathrm{C}$ & $\mathrm{D}$ & $\mathrm{E}$ & $\mathrm{F}$ & $\mathrm{G}$ & $\mathrm{H}$ & $\mathrm{I}$ \\
\hline $\mathrm{A}$ & 1 & 7 & 3 & 9 & 11 & 7 & 8 & 11 \\
\hline $\mathrm{B}$ & & 0 & 0 & 1 & 1 & 0 & 0 & 1 \\
\hline $\mathrm{C}$ & & & 3 & 9 & 11 & 7 & 8 & 11 \\
\hline $\mathrm{D}$ & & & & 3 & 3 & 2 & 2 & 3 \\
\hline $\mathrm{E}$ & & & & & 36 & 22 & 25 & 37 \\
\hline $\mathrm{F}$ & & & & & & 8 & 9 & 12 \\
\hline $\mathrm{G}$ & & & & & & & 7 & 10 \\
\hline $\mathrm{H}$ & & & & & & & & \\
\hline
\end{tabular}

\subsection{Maximum speed control and service pattern}

The following 4 service patterns are considered.

[Pattern 1] Normal-speed driving in all sections.

[Pattern 2] Restraining maximum speed in the former 4 interstations from $A$ to $E$ and normal driving in the latter 4 interstations from $\mathrm{E}$ to $\mathrm{I}$.

[Pattern 3] Restraining maximum speed in the latter 4 interstations from $E$ to I and normal driving in the former 4 interstations from $\mathrm{A}$ to $\mathrm{E}$. [Pattern 4] Restraining maximum speed in all sections. 
Also, the following 3 levels of speed restriction are considered.

(1) Maximum speed $5 \mathrm{~km} / \mathrm{h}$ restraint

(2) Maximum speed $10 \mathrm{~km} / \mathrm{h}$ restraint

(3) Maximum speed $15 \mathrm{~km} / \mathrm{h}$ restraint

Then, Patterns 1-4 are combined with 11 trains in total for each restraint degree (1)-(3). In other words, the authors consider the proposed schedules per hour. Finally, the proposed train schedules are compared with curtailed train schedule in terms of both train energy consumption and total incremental trip time. The final solutions which are better than train curtailed schedule are selected from the pareto-optimal solutions.

\section{Result of calculating energy consumption and trip times}

For example, the results of the speed profile of normal service and restraining maximum speed service are shown in Figures 6 and 7. Energy consumption and trip times per train of 4 service patterns for each restraint level is shown in Table 4.

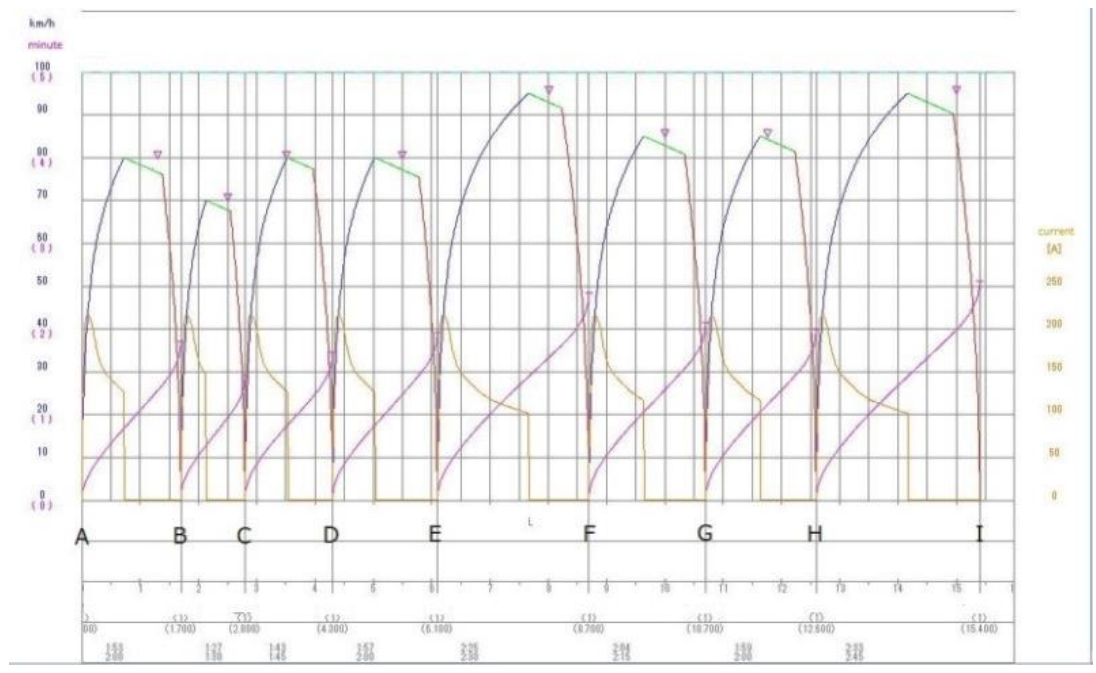

Figure 6: The speed profile of normal service. 


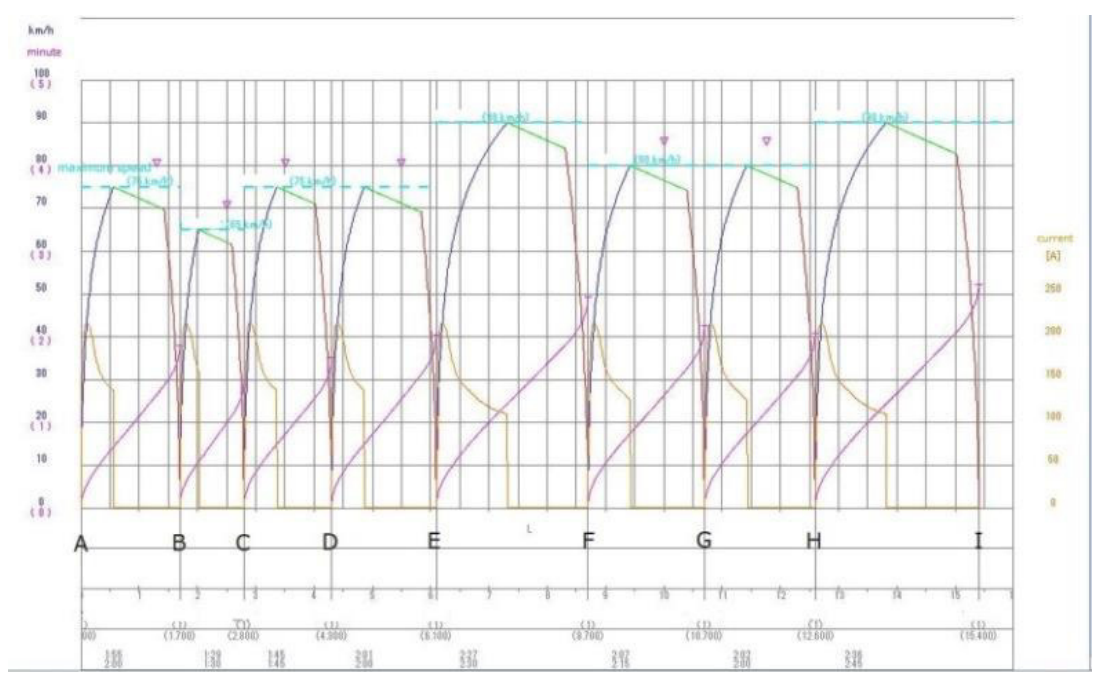

Figure 7: The speed profile of restraining maximum speed service.

Table 4: Energy consumption and trip time of 4 service patterns for each restraint degree.

\begin{tabular}{|c|c|c|c|}
\hline & Service patterns & $\begin{array}{c}\text { Energy consumption } \\
{[\mathrm{kWh}]}\end{array}$ & $\begin{array}{c}\text { Trip times } \\
\text { [minute/train] }\end{array}$ \\
\hline & Pattern 1 & $322.0(0.0)$ & $2994(0)$ \\
\hline \multirow{3}{*}{$\begin{array}{l}\text { (1) Maximum } \\
\text { speed }-5 \mathrm{~km} / \mathrm{h}\end{array}$} & Pattern 2 & $304.7(-17.4)$ & $3008(+14)$ \\
\hline & Pattern 3 & $299.0(-23.0)$ & $3022(+28)$ \\
\hline & Pattern 4 & $281.7(-40.2)$ & $3036(+42)$ \\
\hline \multirow{3}{*}{$\begin{array}{l}\text { (2) Maximum } \\
\text { speed }-10 \mathrm{~km} / \mathrm{h}\end{array}$} & Pattern 2 & $289.7(-32.4)$ & $3030(+36)$ \\
\hline & Pattern 3 & $292.0(-30.0)$ & $3055(+61)$ \\
\hline & Pattern 4 & $259.7(-62.2)$ & $3091(+97)$ \\
\hline \multirow{3}{*}{$\begin{array}{l}\text { (3) Maximum } \\
\text { speed }-15 \mathrm{~km} / \mathrm{h}\end{array}$} & Pattern 2 & $279.4(-42.7)$ & $3055(+61)$ \\
\hline & Pattern 3 & $277.0(-45.1)$ & $3098(+104)$ \\
\hline & Pattern 4 & $234.4(-87.6)$ & $3160(+166)$ \\
\hline
\end{tabular}

\section{Optimization}

From these simulation results, the authors consider the optimal schedules. The patterns and speed restrictions levels are applied to each train. Different patterns and speed restrictions may be combined in a timetable. Energy consumption and total incremental trip time of train curtailed schedule compared with normal schedule are shown in Table 5.

In particular, the pareto-optimal solutions in the solutions which are better than the train curtailed schedule (shown as intersection of two straight lines) are shown in Figure 8. Likewise, the proposed schedules consisted of the combinations of 4 service patterns chosen as pareto-optimal solutions are shown 
Table 5: Energy consumption and total incremental trip time.

\begin{tabular}{|c|c|c|}
\hline & $\begin{array}{c}\text { Energy consumption } \\
{[\mathrm{kWh}]}\end{array}$ & $\begin{array}{c}\text { Total incremental trip } \\
\text { time [minute] }\end{array}$ \\
\hline Normal timetable & 3542.0 & 0 \\
\hline Train curtailed timetable & 2898.0 & 1998 \\
\hline
\end{tabular}



Figure 8: The pareto-optimal solutions better than the curtailed service.

in Table $6[(\mathrm{a})-(\mathrm{t})]$. The numbers $(0-11)$ in Table 6 describe numbers of each service.

As a result, the proposed schedules which are better than the train curtailed schedule are found as pareto-optimal solutions. Compared with train curtailed schedule, schedule (c) has the highest rate of reduction by $11.0 \%$ in terms of energy consumption. On the other hand, schedule (b) has the highest rate of reduction by $49.6 \%$ in terms of total incremental trip time.

\section{Conclusions}

The authors summarized some ideas against power crises and chose the idea of maximum speed restriction as the most feasible and less-drawback one. The efficacy of the proposed method was demonstrated with a case study of one direction service of a double track commuter line. Finally, some pareto-optimal solutions better than the curtailed service in the viewpoint of energy consumption and trip times were found.

The proposed idea can be applied in case of substation failures as well as disasters. Therefore, the idea must be effective not only in Japan but also other countries with few disasters. 
Table 6: The combinations of 4 service patterns chosen as pareto-optimal solutions.

\begin{tabular}{|c|c|c|c|c|c|c|c|}
\hline & Schedule & $\begin{array}{l}\text { Normal } \\
\text { service }\end{array}$ & $\begin{array}{l}4 \text { sections } \\
\text { of first half }\end{array}$ & $\begin{array}{l}4 \text { sections } \\
\text { of last half }\end{array}$ & All sections & $\begin{array}{c}\text { Energy } \\
\text { consumption } \\
{[\mathrm{kWh}]}\end{array}$ & $\begin{array}{c}\text { Total } \\
\text { incremental } \\
\text { trip time } \\
\text { [minute] }\end{array}$ \\
\hline \multirow{2}{*}{$\begin{array}{l}\text { Maximum } \\
\text { speed } \\
-10 \mathrm{~km} / \mathrm{h} \\
\end{array}$} & (a) & 0 & 0 & 0 & 11 & 2857.8 & 1067 \\
\hline & (b) & 0 & 1 & 0 & 10 & 2887.6 & 1006 \\
\hline \multirow{18}{*}{$\begin{array}{l}\text { Maximum } \\
\text { speed } \\
-15 \mathrm{~km} / \mathrm{h}\end{array}$} & (c) & 0 & 0 & 0 & 11 & 2578.4 & 1824 \\
\hline & (d) & 0 & 0 & 1 & 10 & 2620.9 & 1763 \\
\hline & (e) & 0 & 0 & 2 & 9 & 2663.4 & 1701 \\
\hline & (f) & 0 & 1 & 0 & 10 & 2623.3 & 1720 \\
\hline & (g) & 0 & 1 & 1 & 9 & 2665.8 & 1658 \\
\hline & (h) & 0 & 1 & 2 & 8 & 2708.3 & 1597 \\
\hline & (i) & 0 & 2 & 0 & 9 & 2668.2 & 1615 \\
\hline & (j) & 0 & 2 & 1 & 8 & 2710.7 & 1554 \\
\hline & (k) & 0 & 2 & 2 & 7 & 2753.2 & 1492 \\
\hline & (1) & 0 & 3 & 0 & 8 & 2713.1 & 1511 \\
\hline & (m) & 0 & 3 & 1 & 7 & 2755.6 & 1449 \\
\hline & (n) & 0 & 3 & 2 & 6 & 2798.1 & 1388 \\
\hline & (o) & 0 & 4 & 0 & 7 & 2758 & 1406 \\
\hline & (p) & 0 & 4 & 1 & 6 & 2800.5 & 1345 \\
\hline & (q) & 0 & 4 & 2 & 5 & 2843 & 1284 \\
\hline & $(\mathrm{r})$ & 0 & 5 & 0 & 6 & 2802.9 & 1302 \\
\hline & (s) & 0 & 5 & 1 & 5 & 2845.4 & 1241 \\
\hline & (t) & 0 & 6 & 0 & 5 & 2847.8 & 1198 \\
\hline
\end{tabular}

\section{References}

[1] Sone, S., Coping with a Power Crisis, Railway Gazette International, pp. 4750, June 2013.

[2] Hamazaki, Y., Works on Energy Savings in Shinkeisei Electric Railway Co., Rolling Stock \& Technology, Rail and Tech: Japan, No. 196, pp. 15-21, 2012. (in Japanese)

[3] Miyatake, M., Kuwahara, R., \& Nakasa, S., A Simple Adjustment of Runtimes between Stations for Saving Traction Energy by Means of Mathematical Programming, Computers in Railways XIII, pp. 451-460, 2012.

[4] Mizoguchi, H., Miyatake, M., \& Fuse, T., A Study on Train Scheduling to Minimize Trip Time of Passengers under Restricted Electrical Energy Use, IEEJ Transactions on Industry Applications, Vol. 133, No. 7, 2013. (in Japanese)

[5] Miyatake, M. \& Nakasa, S., Train Scheduling under Condition of Restricted Electrical Energy with Considering Energy Consumption and Trip Time, IEEJ Industry Applications Society Conference, No. 5-37, pp. V-229-230, Yamaguchi, 2013. (in Japanese) 
[6] Train Performance Calculation System "SPEEDY" http://www.rtri.or.jp /sales/english/topics/simulation/speedy3.html

[7] Nakamura. H, Yano. T, Theory and application of the multiobjective programming, Corona: Japan, 1994. (in Japanese)

[8] JR characteristics date of cars http://www2.pf-x.net/ just-r/data/jr/JRdclocal2.html\#E231-0 